Volume: 2, Issue: 1, January-March 2017, Pages: 119, DOI: http://dx.doi.org/10.19082/ah119

\title{
EVALUATION OF THE RADIOLOGY INFORMATION SYSTEMS IN PUBLIC TEACHING HOSPITALS IN ISFAHAN UNIVERSITY OF MEDICAL SCIENCES
}

\author{
Shahrzad Amirazodi ${ }^{1}$, Maryam Jahanbakhsh ${ }^{2}$, Elmira Hajizadeh ${ }^{3}$ Safoura Ramezani ${ }^{4}$
}

1: M.Sc of Health Information Technology, Kashan University of Medical Sciences, Kashan, Iran

2: Instructor, Health Information Technology Research Center, Isfahan University of Medical Sciences, Isfahan, Iran

3: M.Sc of Health Information Technology, Tehran University of Medical Sciences, Tehran, Iran

4: B.S of Health Information Technology, Isfahan University of Medical Sciences, Isfahan, Iran

Correspondence:

Shahrzad Amirazodi. Tel: +98.9137395549, E-mail: Amirazoodi@yahoo.com

\section{TYPE OF ARTICLE: CONFERENCE ABSTRACT}

\begin{abstract}
Introduction: Supporting a treatment approach and medical imaging management, radiology information systems (RIS) act as one of the central pillars of health systems. Regarding positive effects of such systems on a patient's treatment process and organization function, it is necessary to evaluate such systems. Thus, the aim of this study was assessment of RIS in the public teaching hospitals in Isfahan University of Medical Sciences based on the guidelines of the Britain Royal College of Radiologists.

Methods: The present study is a descriptive study. The research population included all RIS in the public teaching hospitals in Isfahan University of Medical Sciences. The data collection instrument was self-designed checklist, which consists of 43 criterions regarding (inputs, process, outputs) factors of radiology information systems based on the guidelines of the Britain Royal College of Radiologists; thus, the validity of the compiled checklist was assessed based on the result of the views gathered from professors in the health information management field.

Results: The finding of the study on the RIS in six hospitals showed the mean of compliance inputs factors of RIS is $27.69 \%$, process $37.14 \%$, output $57.77 \%$, and the total amount of compliance criteria (inputs, processes, and outputs) in the RIS is $38.60 \%$.

Conclusion: The findings of study indicate that, based on the Britain Royal College of Radiologists guidelines, RISs measures have been implemented as inappropriate. Therefore, to achieve the desired mode, systems in future development must include more consistent standards of RISs, and more attention should be given to users' informational requirements as well as system expectations.

KEYWORDS: Evaluation, Radiology information System, Hospital
\end{abstract}

\footnotetext{
Abstracts of First National Congress of Medical Informatics, Mashhad, Iran, February 2017

(C) 2017 The Authors. This is an open access article under the terms of the Creative Commons Attribution-NonCommercialNoDerivs License, which permits use and distribution in any medium, provided the original work is properly cited, the use is non-commercial and no modifications or adaptations are made.
} 